УДК 069.01

$10.17213 / 2075-2067-2021-4-57-65$

\title{
РОЛЬ МУЗЕЕВ В СОВРЕМЕННОМ ОБЩЕСТВЕ: ИНСТИТУЦИОНАЛЬНАЯ ПАРАДИГМА
}

\author{
(C) 2021 г. Е. Ю. Литвиненко, Г. П. Гринберг
}

Южно-Российский государственный политехнический университет (НПИ) имени М. И. Платова, г. Новочеркасск, Россия

Целью исследования является обоснование сущуности и специифики музеев как социального института, являющегося альтернативным в системе базовых институтов общества, сформированного благодаря иеленаправленной и креативной деятельности многих поколений людей, нацеленных на воспроизводство и трансляцию конкретной культуры, ее материальных и духовных иенностей.

Методологическую базу исследования представляют классические труды Л. Витгенштейна, Т. Парсонса, посвященные разработке институционально-социологического подхода к анализу базовых институтов общества. Исследование базируется также на коницепции институциональных матриц, разработанной Новосибирской социологической школой (О. Э. Бессонова и С. Г. Кирдина).

Результаты исследования. Роль музеев и их функиии в современном обществе в большинстве исследований рассматриваются в культурологической парадигме как особая форма культуры. При этом недостаточно внимания уделяется рассмотрению музеев в институциональной парадигме, которая позволяет выявить значимость музеев как для социального, так и для сочиетального уровней жизнедеятельности современного общества.

Перспективу исследования составляет дальнейший соичиологический анализ функичонирования современных музеев как особого сочиального института культуры.

Ключевые слова: музеи; социальный институт; культура; институциализация; социум; материальные и духовнье иенности.

\section{THE ROLE OF MUSEUMS IN MODERN SOCIETY: THE INSTITUTIONAL PARADIGM}

\author{
(C) 2021 E. Yu. Litvinenko, G. P. Grinberg
}

\section{Platov South Russian State Polytechnic University (NPI), Novocherkassk, Russia}

The purpose of the study is to substantiate the essence and specificity of museums as a social institution, which is an alternative institution in the system of basic institutions of society, formed thanks to the purposeful and creative activities of many generations of people aimed at reproducing and transmitting a specific culture, its material and spiritual values.

The methodological base of the study is presented by the classical works of L. Wittgenstein, T. Parsons, devoted to the development of an institutional-sociological approach to the analysis of basic institutions of society. The study is also based on the concept 
of institutional matrices developed by the Novosibirsk Sociological School (O. E. Bessonov and S. G. Kirdin).

The results of the study. The role of museums and their functions in modern society in most studies are considered in the cultural and logical paradigm as a special form of culture. At the same time, attention is paid to the consideration of museums in the institutional paradigm, which allows us to identify the significance of museums for both the social and societal levels of the modern society life.

The prospect of the study is a further sociological analysis of the functioning of modern museums as a special social institution of culture.

Key words: museums; social institution; culture; institutionalization; society; material and spiritual values.

Введение. Трансформации, произошедшие и происходящие в обществе во всех его сферах, в том числе и в области культуры, привели к изменениям многих культурных форм, в частности, модифицировалось восприятие музеев лишь как хранителей культурных артефактов. Они стали рассматриваться как один из существенных факторов социализации молодого поколения, который аккумулирует достижения культуры и является механизмом ее трансляции новым поколениям. Об этом свидетельствует и расширение спектра музеев, и их значительное увеличение в количественном измерении. Так, с 1995 по 2010 гг. количество музеев в нашей стране увеличилось почти на $45 \%$ [1]. Появление новых музеев включает не только музеи современного искусства, арт-галереи, но и различные виртуальные музеи, использующие возможности современных компьютерных технологий. Инновационные мероприятия, организуемые музеями, также увеличивают заинтересованность людей в их посещении. Таким значимым мероприятием стала, например, ежегодно проводимая акция «Ночь в музее». Несмотря на то, что, по мнению некоторых исследователей, «музеи не стали еще ни научными центрами, ни воспитательными учреждениями» [2, с. 283], в большинстве научных работ прослеживается идея о том, что музеи расширяют свои социальные функции, которые не только сохраняют и демонстрируют достижения культуры, но и влияют на формирование идентичности и системы ценностей, являясь интегративным компонентом непосредственно культурного сектора, культурно-экономического сектора, общественного (публичного) сектора, а также культурной политики [3]. Современные исследователи музеев и их функций отмечают, что музей в настоящее время в качестве социального института «организует и координирует деятельность людей по сохранению памятников прошлых эпох, без музея эта деятельность имела бы, вероятно, разрозненный, непоследовательный и неустойчивый характер» [4, с. 177]. Все это говорит о том, что музей сегодня является макросоциологическим концептом, который характеризуется различными организационными формами, специфическими локальными структурами, правилами и конвенциями, которые определяют социальные действия внутри данной сферы культуры. Становится очевидным, что исследование музеев как института культуры должно концентрироваться на следующих аспектах:

- культурные интерпретации и оценки (например, произведения искусства, аудитория медиа, критика искусства);

- социальные отношения внутри культурных практик (взаимодействие между профессионалами, интеракция с аудиторией);

- взаимодействие между отдельными культурными организациями и социальной окружающей средой.

Музей как социальный институт. Если обратиться к трактовке понятия «институт», данной Российской социологической энциклопедией, то можно увидеть, что терминологически феномен социального института «...подразумевает возможность обобщения абстрагированных из многообразных действий людей наиболее существенных типов деятельности и социальных отношений, пу- 
тем соотнесения их с фундаментальными целями и потребностями социальной системы» [5, с. 197]. В настоящее время термин «социальный институт» в контексте социального дискурса рассматривается в качестве «... устойчивого комплекса формальных и неформальных правил, принципов, норм и установок, регулирующих различные сферы человеческой деятельности» [6, с. 117]. При этом институты следует не только идентифицировать с организационными формами (например, театры, галереи, музеи, издательские дома), но и принимать во внимание эксплицитное правило (юридические нормы, установленные нормативные профессиональные виды деятельности), формы обмена (рынки, социальный престиж), а также имплицитные конвенции, поведенческие паттерны, такие как социальные роли, формирующие и стабилизирующие практики профессиональной деятельности. Благодаря их структуре, сфера культурных институтов, в том числе музеев, конституирует практические рамки и способствует регулярности деятельности в контексте существующих традиций и инновационных форм, возникающих в них в результате трансформации социокультурной жизни современных обществ [7].

В рамках социологии институциональный подход к исследованию культурных институтов отличается от большинства функционалистских концепций, поскольку институты культуры не только регулируют социальные действия, но они также формируются социальными действиями. Как подчеркивал Людвиг Витгенштейн, следует понимать, что социальная область действия, конституирующая институты, является только частью социальных практик, поскольку институты структурируют социальное действие, но не определяют его [8]. Институциональный подход особенно внимательно исследует те социальные структуры, которые были сформированы благодаря человеческой деятельности в течение социально-исторического развития человечества, порождая такие социальные связи, вступление в которые становится предопределенным и воспроизводимым в разнообразной человеческой деятельности. В связи с тем, что институт музеев становится все более и более вовлеченным в процесс глобализации, он начинает выполнять существенную социальную и политическую функцию, для чего постоянно разрабатываются инновационные формы артикуляции и репрезентации, что, безусловно, улучшает и расширяет социальные коммуникации между музеями, в том числе и на международном уровне. Институт музеев становится областью политических, культурных и социальных переговоров, сглаживая существующие противоречия и недопонимания между представителями различных культур.

Основные характеристики института музея могут быть рассмотрены в рамках их функций и их смысловым содержанием, что позволяет выделить акторов, осуществляющих определенные функции, виды музеев (государственные, частные, корпоративные, образовательные и т.д.), каждый из которых нацелен на удовлетворение культурных запросов определенной аудитории. Как отмечает Л.Я. Петрунина, вовлечение в деятельность музеев широких слоев населения (волонтеров, частных коллекционеров, различных гражданских организаций), приводит к тому, что музей все больше интегрируется в систему «прочих социальных институтов наряду с институтами семьи, религии, политических партий, образования и т.д.» [9, с. 135].

Музей как традиционный социальный институт представлял совокупность лиц (музейные работники, администрация музеев, охранники музеев и др.), учреждений (сами музеи, органы культуры, осуществляющие руководство деятельностью музеев, администрация конкретных регионов, международные организации и т.д.), материальные ценности музеев. Однако в настоящее время отмечается тренд по «адаптации» института музея к постоянно трансформирующейся социально-экономической и социально-культурной ситуации. В качестве примеров такой культурной адаптации можно привести:

— «музейные гастроли» - организацию театральных постановок известных драматургов и писателей в усадьбах-заповедниках;

- проведение так называемых пленэров, некоторые из них выходят на международный уровень (пленэр «Зеленый шум»);

- работа музеев по возрождению этнографических традиций;

- трансформация статуса различных небольших центров до статуса музеев (напри- 
мер, появление таких музеев, как музей «Русского зарубежья», музей «Истории миграции»).

Эта инновационная деятельность музеев позволяет говорить о том, что усиливается роль института музеев «как современного центра социальных изменений», стремящегося удовлетворить потребности в «культурной пище» различных социальных групп [9, с. 138].

Каждый социальный институт, включая институты культуры, к которым относятся и музеи, имеет конкретные цели, детерминированные выполняемыми функциями, социокультурной ролью в обществе, обеспечивая тем самым выполнение этих конкретных целей, зависящих от политических, экономических и культурных условий существования общества в континууме его исторического развития. Что касается музеев, то их функции как социального института расширяются по мере развития обществ. Отмечается, что на первом этапе институционализации музеев, который был достаточно пролонгированным, начиная с первого тысячелетия до нашей эры до середины XVIII века, музеи постепенно сформировались как специфический институт культуры, получивший развитие в период с последней трети XVIII в. и практически до последнего десятилетия XIX в., когда четко обозначаются области конкретной деятельности музеев. Окончательное структурирование музеев и их формирование как инструмента трансляции культуры от поколения к поколению происходит начиная от конца XIX — начала XX века до конца XX века [10]. Если базовая функция музея как социального института, а именно - функция охраны ценностей, существует с самого начала существования музеев, то научно-исследовательская функция появляется, когда возникает необходимость систематизации накопленных ценностей, в то время как научно-просветительская функция появляется по мере демократизации общества [11]. Последняя функция играет немаловажную роль в социализации индивидов, поскольку способствует интериоризации основных культурных достижений общества, представляющих собой так называемое «ядро культуры», в которое входят базисные ценности, нормы, а также артефакты культуры, являющиеся неотъемлемым наследием, без которого не мыслится национальная культура.
Музеи как социетальный институт. Социальные институты, которые определяются как основные (базисные) в своем скоординированном и постоянном взаимодействии формируют социетальную сферу общества, определение которой связано, в первую очередь, с Т. Парсонсом, отмечавшим, что «ядром общества как разновидности социальной системы является ... его интегративная подсистема, которая ... обеспечивает или не обеспечивает различные порядки и уровни внутренней интеграции» $[12$, с. 23]. Основными функциями социетальной сферы, сформулированными Т. Парсонсом, являются следующие: адаптационная функция, целедостижительная функция, структурно-сохраняющая функция, интегративная функция.

Следует отметить, что социетальная сфера образуется в контексте постоянного взаимодействия социальных групп, общностей, которое во многом осуществляется благодаря функционированию институтов в сфере культуры, где значимую роль играет институт музеев, так как на основании сохранения и трансляции общих культурных паттернов в сознании людей формируются солидарные связи в обществе. Следовательно, музеи, выполняя роль одного из главных «резерваторов» культуры, сохраняют не только материальные и духовные ценности культуры, но и способствуют «внедрению» в жизнь общества определенных социокультурных ориентиров, тем самым предоставляя поле креативной деятельности для проактивных социальных акторов [13, с. 20]. На протяжении всего времени институционализации музеев они испытывали на себе укорененные ценности, верования и представления, сложившиеся в ходе формирования культуры. Вследствие приверженности к традиционным культурным ценностям и установкам даже в условиях бурного развития информационных технологий, а в конечном итоге и информационного общества, резервируются ценностные смыслы, присущие культуре. В данном контексте институт музеев частично воспроизводит устоявшиеся нормы взаимодействия, корпоративные связи, определяющие основные цели его функционирования. Поэтому, несмотря на различные инновации, появляющиеся в деятельности ныне существующих музеев, «специфические музейные 
ценности и правила поведения, являющиеся атрибутом музейной действительности, прочно закрепились в морали и праве общества» $[13$, c. 22].

Между тем, ни один социальный институт не функционирует как единичное образование, все социальные институты постоянно взаимодействуют, поскольку их деятельность служит удовлетворению нужд (потребностей) определенного социального субъекта. Учитывая эту взаимозависимость и взаимообусловленность функционирования социальных институтов, опираясь на институциональную парадигму в социологии, российские ученые О.Э. Бессонова и С.Г. Кирдина выделили институциональные матрицы, что позволило определить социальные институты как «... глубинные, исторически устойчивые формы социальной практики, обеспечивающие воспроизводство социальных связей и отношений в разных типах обществ, ... которые позволяют обществу выживать и развиваться, сохраняя свою самодостаточность и целостность в ходе исторической эволюции, независимо от воли и желания конкретных субъектов» [14, с. 17]. Что касается института музеев, несомненным видится то, что он относится именно к социетальным институтам, способствующим сохранению и поддержанию целостности общества (государства) и его культурообразующих областей. В этом отношении институт музеев функционирует, развивается и видоизменяется в тесном взаимодействии со всеми институтами культуры, и прежде всего, с институтом образования.

С.Г. Кирдина выделяет базисные и дополняющие институты существующего общества в зависимости от их функциональной значимости: «Для базовых институтов, соответствующих типу институциональной матрицы данного общества, в большей мере характерен спонтанный, стихийный характер. Развитие же альтернативных, вспомогательных институтов, обеспечивающих во взаимодействии с базовыми институтами сбалансированное функционирование той или иной общественной сферы, требует целенаправленных усилий со стороны социальных субъектов» [15, с. 32]. Опираясь на данный подход, можно прийти к выводу, что развитие института музеев происходит согласно определенной логике, зависящей от культурной политики и целей, определяемых культурноэкономическим сектором (культурные объекты, объем культурной продукции, занятость в культурной сфере, спонсорство и т.д.), и публичного сектора (рецепция и потребление культурной продукции, культурная идентичность и гражданское общество, культура и политическая артикуляция и т.д.). Для упорядочивания функционирования института музеев создаются различные организации. Так, например, одной из таких влиятельных и эффективно работающих организаций стал Международный совет музеев (ИКОМ), сформировавший и распространивший по всему миру Этический музейный кодекс, согласно которому музей трактуется как «постоянно действующее некоммерческое учреждение, призванное служить обществу и способствовать его развитию, доступное широкой публике, занимающееся исследованием, приобретением, хранением, популяризацией и экспонированием материальных свидетельств о человеке и его среде обитания в целях изучения, образования и удовлетворения духовных потребностей» [16, с. 46].

Рассмотрение музея в качестве социетального института обусловливается тем, что индивиды социализируются внутри культурного окружения, которое влияет на их язык, систему ценностей, традиции и т.д. Исторически музеи были созданы, чтобы сохранить вещи, которые представлялись ценными для некоторых членов общества, для других же они могли никакой ценности не нести. Данное различное восприятие к содержательной части музеев влияет на индивидуальные и коллективные потребности посетителей музеев, очерчивая их экспектации по отношению к музеям - существуют ли данные институции для них и предлагают ли они то, что представляется для них ценным и значимым. Для тех, кто действительно заинтересован в посещении музеев, это восприятие влияет на степень удовлетворенности от посещения того или иного музея. Различное восприятие музеев во многом обусловлено тем, что музей представляет сакрально-культурную сущность, созданную людьми в соответствии с их культурными ценностями и предубеждениями. Поэтому впечатление, которое получает посетитель музея, может согласовываться с ценностями и убеждениями создателей му- 
зеев, или же, напротив, вызывать отторжение. Как музеи в качестве социетального института определяют форму, интеракцию, и в какой степени они находятся под воздействием индивидуальных и коллективных потребностей, является ключом для понимания, почему только определенная часть людей регулярно посещает музеи. Это является существенным вопросом, так как музеи XX века стремятся быть релевантными для большего количества людей как в экономическом, так и в культурном отношении, и понимание того, почему они удовлетворяют культурные потребности только определенной части людей, может помочь в формировании стратегии развития музеев и их функционировании.

Для понимания вышеобозначенной проблемы были проведены многочисленные исследования в разных странах. В результате, например, было выявлено, что в таких странах, как США и Австралия ,60-70\% от всех посетителей составляют семьи, 20-35\% - группы школьников или группы туристов и только $5 \%$ составляют индивидуальные посещения. Такой же тренд отмечается в Дании и других развитых странах [17]. При этом было замечено, что вследствие того, что посещения носят, как правило, коллективный характер, люди в большей степени запоминают не содержание экспонатов (выставок), а тех, с кем они посещали музеи, и наиболее запомнившиеся аспекты коммуникации между членами группы. Более того, определенная часть людей посещает музеи именно с целью интеракции с другими. Именно поэтому современные музеи столько внимания уделяют разработке и внедрению в работу музеев различных интерактивных программ. Согласно институциональной парадигме, различные формы существования институтов культуры, в том числе и института музеев, зависят от желания общества по их сохранению и развитию. В данном контексте тенденция по демократизации института музея выражается в инклюзии в его функционирование региональных и локальных музеев, стремящихся продемонстрировать уникальность культуры и истории, характерных для данной территории. Поэтому для развития региональных музеев столь значимым становится выбор культурного ядра (базисных локальных ценностей), которое презентует специфику историко-культурного наследия. Так, например, в построенном в Ижевске по инициативе В. В. Путина музейно-выставочном комплексе выбор был сделан в пользу военно-патриотического бренда. Историко-краеведческий бренд был выбран для Челябинской и Московской областей, национальная история стала символом Республики Тува, Чеченской республики. Выросла роль музеев в качестве формирования бренда территории, превращающегося в своеобразный «имиджевый инструмент», способствующий привлекательности того или иного региона в различных его проявлениях - историческом, географическом, индустриальном, культурном [18].

Заключение. Институциональный подход в исследовании музеев как одного из институтов культуры позволяет объяснить имплицитное воспроизводство культурных практик, где действия происходят не в «ничейном пространстве», но в социальном пространстве, где взаимодействуют различные социальные институты и где институт музеев можно определить как механизм, формирующий и поддерживающий целостное единство и культурное своеобразие конкретного общества, которое образуется благодаря корпоративному взаимодействию культурно-экономического сектора, общественного сектора, культурного сектора, а также культурной политики, осуществляемой как на государственном уровне, так и в конкретных региональных образованиях.

Таким образом, в деятельности института музеев, видимо, просматриваются две компоненты:

- социальная, нацеленная на удовлетворение культурных потребностей общества, чтобы сохранить, поддержать, а в некоторых случаях возродить культурные ценности, отвечающие культурной политике государства и гражданского общества для резервирования культурного наследия и передачи его будущим поколениям;

- социетальная, которая обеспечивает вышеобозначенные потребности конкретными формами и средствами, соответствующими представлениям о культурном «коде» того или иного общества. 


\section{Литература}

1. Статистика. Музеи [Электронный доступ] // Госкомстат. - Режим доступа: http:// www.gks.ru/bgd/regl/b11_11/IssWWW.exe/stg/ d1/10-03.htm/.

2. Лихачев Д. С. Заметки и наблюдения: Из записных книжек разных лет. - Л.: Советский писатель, 1989.

3. Hasidschka W., TschmuckP., Zembylas T. Cutural Institutions Studies: Investigating the Transformation of Cultural Goods// The Journal of Arts Management, Law and Society. - 2005. - Vol. 35. - №2. - Pp. 147-158.

4. Дунаева С.В. Аспекты функционирования музея как особого социального института // Актуальные проблемы гуманитарных и естественных наук. - 2010. C. 177-183.

5. Комаров М.С. Введение в социологию. - М.: Наука, 1994. - С. 197.

6. Современная западная социология: Словарь. - М., 1990.

7. Дунаева С.В. Философский аспект трансформации роли музея как социального института и его положение в современном обществе // Вестник Ленинградского государственного ун-та им. А.С. Пушкина. 2011. - C. 197-204.

8. Витгенштейн Л. Философские работы / Пер. с нем. М. С. Козловой и Ю. А. Асеева. — Ч. І. — М.: Гнозис, 1994.

9. Петрунина Л.Я. От традиционного музея к социальному институту // Вопросы музеологии. - 2020. - Т. 11. - Вып. 1. C. $133-140$.

10. Tschmuck P. How Creative Are the Creative Industries? The Case of the Music Industry // Journal of Arts Management, Law, and Society. - 2003. - №33 (2). - Pp. 127-141.

11. Российская социологическая энциклопедия. - М., 1998.

12. Парсонс T. Система современных обществ. - М.: Аспект Пресс, 1998.

13. Гриикевич В.П. История музейного дела до конца XVIII века. - СПб.: СПбГУКИ, 2004.

14. Кулемзин А. М. Современные прогрессивные тенденции в музейном деле // Музееведение и историко-культурное наследие: Сб. статей. - Кемерово: Кемеровский гос. ун-т культуры и искусств, 2008.
15. Федоров Н.В.: К 175-летию со дня рождения и 100-летию со дня смерти. Антология: в 2 кн. - Т. 1. - СПб.: Изд-во Русского Христианского гуманитарного института, 2004.

16. Этический кодекс ИКОМ для музеев. - М.: Институт России, 2003.

17. Юхневич М.Ю. Три условия // Мир музея. - 2004. - №9. - С. 22-25.

18. Gether Chr. The Art Museums - Still an Institution in Transition // Museums / Social Learning Spaces and Knowledge Producing Process. - Pp. 102-116.

\section{References}

1. Statistika. Muzei [Statistics. Museums] [Jelektronnyj dostup] // Goskomstat. — URL: http://www.gks.ru/bgd/regl/b11_11/IssWWW. exe/stg/d1/10-03.htm/.

2. Lihachev D.S. Zametki i nabljudenija: Iz zapisnyh knizhek raznyh let [Notes and observations: From notebooks of different years]. Leningrad: Sovetskij pisatel', 1989.

3. Hasidschka W., TschmuckP., Zembylas T. Cutural Institutions Studies: Investigating the Transformation of Cultural Goods // The Journal of Arts Management, Law and Society. - 2005. - Vol. 35. - №2. - Pp. 147-158.

4. Dunaeva $S$. $V$. Aspekty funkcionirovanija muzeja kak osobogo social'nogo instituta [Aspects of the functioning of the museum as a special social institution] // Aktual'nye problemy gumanitarnyh i estestvennyh nauk [Actual problems of the humanities and natural sciences]. 2010. - Pp. 177-183.

5. Komarov M.S. Vvedenie v sociologiju [Introduction to sociology]. - Moscow: Nauka, 1994. - P. 197.

6. Sovremennaja zapadnaja sociologija: Slovar' [Modern Western Sociology: Dictionary]. - Moscow, 1990.

7. Dunaeva $S . V$. Filosofskij aspekt transformacii roli muzeja kak social'nogo instituta $\mathrm{i}$ ego polozhenie $\mathrm{v}$ sovremennom obshhestve [The philosophical aspect of the transformation of the role of the museum as a social institution and its position in modern society] // Vestnik Leningradskogo gosudarstvennogo un-ta im. A. S. Pushkina [Bulletin of the Leningrad State University named after A. S. Pushkin]. 2011. - Pp. 197-204. 
8. Vitgenshtejn L. Filosofskie raboty [Philosophical works] / Per. s nem. M. S. Kozlovoj i Ju. A. Aseeva. - Part I. - Moscow: Gnozis, 1994.

9. Petrunina L. Ja. Ot tradicionnogo muzeja k social'nomu institutu [From a traditional museum to a social institute] // Voprosy muzeologii [Questions of museology]. — 2020. Vol. 11. - Issue 1. - Pp. 133-140.

10. Tschmuck P. How Creative Are the Creative Industries? The Case of the Music Industry// Journal of Arts Management, Law, and Society. - 2003. - №33 (2). - Pp. 127-141.

11. Rossijskaja sociologicheskaja jenciklopedija [Russian Sociological Encyclopedia]. Moscow, 1998.

12. Parsons T. Sistema sovremennyh obshhestv [The system of modern societies]. — Moscow: Aspekt Press, 1998.

13. Grickevich V.P. Istorija muzejnogo dela do konca XVIII veka [The history of museum business until the end of the XVIII century]. Saint Petersburg: SPbGUKI, 2004.

14. Kulemzin A.M. Sovremennye progressivnye tendencii $\mathrm{v}$ muzejnom dele [Modern progressive trends in museum business] // Muzeevedenie i istoriko-kul'turnoe nasledie: $\mathrm{Sb}$. statej [Museology and historical and cultural heritage: Collection of articles]. - Kemerovo: Kemerovskij gos. un-t kul'tury i iskusstv, 2008.

15. Fedorov N. V.: K 175-letiju so dnja rozhdenija i 100-letiju so dnja smerti. Antologija: v 2 kn. [Fedorov N. V.: To the 175th anniversary of his birth and the 100th anniversary of his death. Anthology: in 2 books]. - Vol. 1. - Saint Petersburg: Izd-vo Russkogo Hristianskogo gumanitarnogo instituta, 2004.

16. Jeticheskij kodeks IKOM dlja muzeev [The ethical code of ICOM for museums]. Moscow: Institut Rossii, 2003.

17. Juhnevich M. Ju. Tri uslovija [Three conditions] // Mir muzeja [The world of the museum]. - 2004. — №9. - Pp. 22-25.

18. Gether Chr. The Art Museums - Still an Institution in Transition // Museums / Social Learning Spaces and Knowledge Producing Process. - Pp. 102-116.

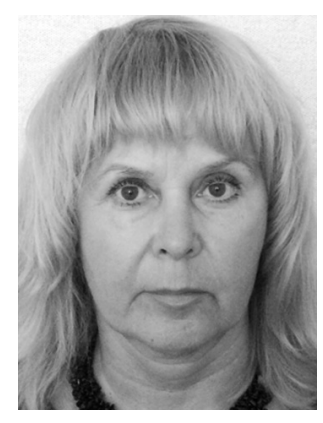

Литвиненко Елена Юрьевна - доктор социологических наук, профессор, профессор кафедры иностранных языков и профессиональных коммуникаций Южно-Российского государственного политехнического университета (НПИ) им. М. И. Платова.

Litvinenko Elena Yurievna - Doctor of Sociological Sciences, Professor the Foreign Languages for Professional Communications Department, South-Russian State Polytechnic University (NPI).

346428 , г. Новочеркасск, ул. Просвещения, 132 132 Prosveshcheniya st., 346428, Novocherkassk, Russia E-mail: denis.rimma@mail.ru 


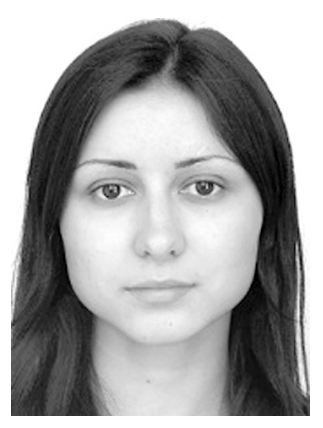

Гринберг Галина Павловна - аспирант первого года обучения направления «Социологические науки 39.06.01», старший преподаватель кафедры «Иностранные языки» Южно-Российского Государственного Политехнического Университета (НПИ) имени М.И. Платова.

Grinberg Galina Pavlovna - 1st-year Postgraduate of course «Sociological Sciences 39.06.01», Senior Teacher of «Foreign Languages» Department, Platov South Russian State Polytechnic University (NPI).

346410 , г. Новочеркасск, ул. Комитетская, 47, кв. 29

47 Komitetskaya st., ap. 29, 346410, Novocherkassk, Russia

E-mail: galusya92120109@rambler.ru 